\title{
Clinico-pathological Evaluation of PPR in a Flock of Ganjam Sheep and Goat in Odisha
}

\author{
Prasana Kumar Rath ${ }^{1 *}$, Susen Kumar Panda ${ }^{1}$, Bidyut Prava Mishra², Dillip Kumar Karna ${ }^{3}$, \\ Gyana Ranjan Sahoo ${ }^{4}$, Umakanta Mishra ${ }^{5}$ and Ramesh Chandra Patra ${ }^{6}$ \\ ${ }^{1}$ Department of Veterinary Pathology, College of Veterinary Science $\mathcal{E}$ Animal Husbandry, Odisha University of Agriculture $\mathcal{E}$ \\ Technology, Bhubaneswar, Odisha, INDIA \\ ${ }^{2}$ Department of Livestock Products Technology, College of Veterinary Science \& Animal Husbandry, Odisha University of \\ Agriculture E Technology, Bhubaneswar, Odisha, INDIA \\ ${ }^{3}$ OIC, AICRP on Goat Improvement, College of Veterinary Science \& Animal Husbandry, Odisha University of Agriculture $\mathcal{E}$ \\ Technology, Bhubaneswar, Odisha, INDIA \\ ${ }^{4}$ Department of Veterinary Biochemistry, College of Veterinary Science $\mathcal{E}$ Animal Husbandry, Odisha University of Agriculture $\mathcal{E}$ \\ Technology, Bhubaneswar, Odisha, INDIA \\ ${ }^{5}$ Department of Veterinary Anatomy \& Histology, College of Veterinary Science E Animal Husbandry, Odisha University of \\ Agriculture E Technology, Bhubaneswar, Odisha, INDIA \\ ${ }^{6}$ Department of Veterinary Clinical Medicine, College of Veterinary Science E Animal Husbandry, Odisha University of \\ Agriculture \& Technology, Bhubaneswar, Odisha, INDIA \\ "Corresponding author: PK Rath; E-mail: drpkrath78@gmail.com
}

Received: 10 May, 2020

Revised: 16 June, 2020

Accepted: 27 June, 2020

\begin{abstract}
Present study was aimed to investigate the mortality among a flock of Ganjam sheep and goat during December, 2016 in Odisha. These breed of small ruminant mostly reared in nomadic pattern by certain "Gola" community with native tract mostly in south-eastern and eastern-ghat of agroclimatic zones in Odisha with hot and humid climate. Clinical signs and gross lesions as observed among the animals were indicative of Peste des petits ruminants (PPR). There was nearly $90 \%$ morbidity and $42.22 \%$ mortality. Higher mortality was recorded among the weaners $(\sim 63 \%)$ followed by kids $(\sim 42 \%)$. Blood examination revealed anemia with significantly $(\mathrm{p} \leq 0.05)$ decrease in total erythrocyte counts (TEC) and packed cell volume (PCV) through t-test. Affected animals showed leucocytosis with nutrophillia and lymphopaenia. Statistically significant $(\mathrm{p} \leq 0.05)$ alterations in various serum biochemical parameters were evident in morbid animals. At necropsy, typical lesions were erosive as well as hemorrhagic lesions in buccal mucosa, abomasums and intestine along with fibrinous bronchopneumonia. Histopathological changes were mostly infiltrations of inflammatory cells, syncytia and presence of intranuclear and /or intracytoplasmic eosinophillic inclusions in epithelial cells, alveolar macrophages, lungs and hepatocytes.
\end{abstract}

\section{HIGHLIGHTS}

(0 Pathology of PPR in Ganjam breeds of sheep and goats in Odisha.

(0 Hot humid climate, nomadic pattern of rearing of Ganjam sheep and goats by "Gola community" were incrementing factors for PPR.

Keywords: Ganjam goat, Ganjam sheep, mortality, pathology, PPR

Peste des petits ruminants (PPR) is an important emerging disease among small ruminants causing large scale mortality and morbidity among small ruminants results a huge economic loss. The causative agent of this disease is
How to cite this article: Rath, P.K., Panda, S.K., Mishra, B.P., Karna, D.K. Sahoo, G.R., Mishra, U. and Patra, R.C. (2020). Clinico-pathological evaluation of PPR in a flock of Ganjam sheep and goat in Odisha. J. Anim. Res., 10(4): 585-591.

Source of Support: None; Conflict of Interest: None 
a RNA virus belonged to morbilli virus under the family Paramyxoviridae (Gibbs et al., 1979). India considered as enzootic for this disease with report of regular disease outbreaks occurring in various parts throughout the year (Balamurugan et al., 2012). Though goats and sheep of various ages, sexes and breeds are susceptible but more severity is seen in goats. Ganjam breed of sheep and goat native to southern parts of Odisha are maintained mostly by "Gola community" with a nomadic pattern of domestication. Most of the native tract of these breeds bordering to states like Andhra Pradesh and Chattisgarh. Overall sero-prevalence of PPR in Odisha was $48.42 \%$ (Hota et al., 2017) with $51.21 \%$ and $44.7 \%$ in goats and sheep respectively. Ganjam breeds mostly populated to north eastern, south-eastern and Eastern Ghats agroclimatic zones with hot and humid climate. Ganjam goats are tall and leggy animals, locally known as "Dalua" considered as a dual purpose breed having more body weight $(\sim 30-40 \mathrm{~kg})$ in adults with single litter size. Ganjam sheep are medium sized animals with dark tan color body coat with white patches on face and body. Most of the flocks have both goats and sheep co-housed together in open field with nomadic rearing. There is no available literature as yet regarding the detail pathology of PPR in Ganjam breeds. Present study was aimed to record details of pathology associated with PPR in Ganjam breeds of sheep and goats.

\section{MATERIALS AND METHODS}

After obtaining information about mortality among Ganjam goats and sheep in a flock from the local veterinarian and as per the request of animal owner during December, 2016, a detail investigation was carried out to arrive at the tentative diagnosis of the disease. A questionnaire was prepared for obtaining demographic information like immunization and deworming status, age, management system etc from the animal owners to derive certain epidemiological risk factors favoring the disease outbreak. Clinical signs of all affected small ruminants were recorded. Blood examinations ( $\mathrm{n}=23$ : Goats-14, Sheep-9) were conducted to evaluate changes in various parameters to know the disease severity. Various serum ( $\mathrm{n}=23$ : Goats-14, Sheep-9) biochemical parameters were estimated in automatic biochemical analyzer (TurboChem 100) using commercially available ICHEM kits. Necropsy $(n=7)$ was conducted at the outbreak site to note the morbid changes in different organs. Representative tissue samples approximately $1-2 \mathrm{~cm}$ were cut from all vital organs during postmortem examinations and subjected for fixation in $10 \%$ neutral formalin overnight. Routine histopathology was conducted by using these formalin fixed tissue samples through paraffin embedding with haematoxyline and eosin staining in the Department of Veterinary Pathology of the college to observe various microscopic lesions related to PPR.

\section{Ethical approval and informed consent}

Present study was not subject to ethical approval as no clinical samples from healthy animals collected for the study. Oral consent was taken from the animal owner before drawing blood for outbreak investigation. Blood samples less than $5 \mathrm{ml}$ collected only from clinically ill small ruminants by the concerned registered professional field veterinarian of the area to investigate the disease in outbreak situation for clinical diagnosis of the disease at earliest.

\section{Statistical analysis}

One sample t-test was conducted by using SAS software in each of the hematological and serum biochemical parameters and it was compared with reference population mean (Table $1 \&$ Table 2 ) as per reference values given in Benjamin (2005).

\section{RESULTS AND DISCUSSION}

\section{Epidemiological risk factors}

The said mixed flock comprising of goats $(n=31)$ cohoused with sheep $(n=14)$ in an open field near the foot hill recorded mortality of 19 small ruminants (goats-13, Sheep-06) during the study with overall mortality of $42.22 \%$ and morbidity of $90 \%$. Variation in morbidity and mortality rate among the small ruminants attributed to circulating virus strain in the concerned area, susceptibility of specific breeds, availability of veterinary health care facility and pre-existing bacterial, fungal or parasitic infection as well as animal's own immune status (Banyard et al., 2010).

All the small ruminants were grouped into kids $(\leq 3$ 
Table 1: Mean \pm SE of hematological indices in PPR affected Ganjam sheep and goats

\begin{tabular}{llllll}
\hline Parameters & Species & $\begin{array}{l}\text { Reference } \\
\text { Mean }\end{array}$ & Mean \pm SE & DF & p-value* \\
\hline $\mathrm{Hb}$ & Goats & 10.0 & $6.4 \pm 0.14$ & 13 & $<0.0001$ \\
& Sheep & 10.0 & $6.68 \pm 1.13$ & 8 & $<0.0001$ \\
$\mathrm{TEC}$ & Goats & 13.0 & $9.31 \pm 0.28$ & 13 & $<0.0001$ \\
& Sheep & 13.0 & $9.93 \pm 0.25$ & 8 & $<0.0001$ \\
$\mathrm{PCV}$ & Goats & 30.0 & $18.2 \pm 0.43$ & 13 & $<0.0001$ \\
& Sheep & 30.0 & $19.3 \pm 0.89$ & 8 & $<0.0001$ \\
$\mathrm{TLC}$ & Goats & 8.5 & $19.57 \pm 0.50$ & 13 & $<0.0001$ \\
& Sheep & 8.5 & $19.28 \pm 0.71$ & 8 & $<0.0001$ \\
$\mathrm{~N}$ & Goats & 39.0 & $53.64 \pm 0.38$ & 13 & $<0.0001$ \\
& Sheep & 39.0 & $52.22 \pm 0.96$ & 8 & $<0.0001$ \\
$\mathrm{~L}$ & Goats & 60.0 & $42.92 \pm 0.30$ & 13 & $<0.0001$ \\
& Sheep & 60.0 & $43.88 \pm 0.65$ & 8 & $<0.0001$ \\
\hline
\end{tabular}

${ }^{*} \mathrm{p} \leq 0.05$ means significant between the variables.

Table 2: Mean \pm SE of serum biochemical indices in PPR affected Ganjam sheep and goats

\begin{tabular}{llllll}
\hline Parameters & Species & Reference Mean & Mean \pm SE & DF & $\begin{array}{l}\text { p-value } \\
\text { Glucose }\end{array}$ \\
& Goats & 62.0 & $42.57 \pm 0.33$ & 13 & $<0.0001$ \\
AST & Sheep & 62.0 & $42.04 \pm 0.54$ & 8 & $<0.0001$ \\
& Goats & 300.0 & $323.1 \pm 4.37$ & 13 & $<0.0002$ \\
ALT & Sheep & 300.0 & $338.1 \pm 1.07$ & 8 & $<0.0001$ \\
& Goats & 33.0 & $47.88 \pm 0.21$ & 13 & $<0.0001$ \\
Creatinine & Sheep & 33.0 & $48.17 \pm 0.25$ & 8 & $<0.0001$ \\
& Goats & 1.3 & $3.08 \pm 0.15$ & 13 & $<0.0001$ \\
BUN & Sheep & 1.3 & $2.73 \pm 0.23$ & 8 & $<0.0003$ \\
& Goats & 20.0 & $30.05 \pm 0.85$ & 13 & $<0.0001$ \\
Sodium $\left(\mathrm{Na}^{+}\right)$ & Sheep & 20.0 & $33.88 \pm 0.66$ & 8 & $<0.1297$ \\
& Goats & 148.0 & $153.0 \pm 3.09$ & 13 & $<0.0001$ \\
Chloride $\left(\mathrm{Cl}^{-}\right)$ & Sheep & 148.0 & $141.7 \pm 0.70$ & 8 & $<0.0001$ \\
& Goats & 112.0 & $136.5 \pm 1.47$ & 13 & $<0.0001$ \\
\hline
\end{tabular}

${ }^{*} \mathrm{p} \leq 0.05$ means significant between the variables, Non-significant at $\mathrm{P}>0.05$.

months, $\mathrm{n}=12$ ), weaner (4-9months, $\mathrm{n}=19$ ) and adults ( $>9$ months, $\mathrm{n}=14$ ) according to their age groups. More mortality was observed among weaners $(63.15 \%, n=12)$ followed by kids $(41.66 \%, \mathrm{n}=5)$ and adults $(14.28 \%, \mathrm{n}=2)$. Present findings were consistent with Gupta et al. (2007). Decreased maternal antibody, poor management system by illiterate farm owners, unreached veterinary healthcare facility due to pastoralist system of rearing as well as nutritional imbalance might be responsible for increased mortality rate in weaners as compared to adults and kids with presence of protective antibody due to previous infection or through colostrums respectively (Islam et al., 2012).

Anamnesis was taken from the animal owner suggested about no vaccination as well as deworming since last six months in the flock. There was history of inclusion of two bucks and three does purchased from the adjacent state before seven days. Increased occurrence of PPR in non-vaccinated flocks as reported might be attributed to absence of protective antibody (Islam et al., 2012). Preexisting parasitic infection resulting malnutrition and poor body condition predisposes the animals to succumb 
with a variety of diseases (Pope et al., 2013). Exchange of animals as well as mixing of newly purchased one from nearby livestock market or from adjacent state in the susceptible flock may be regarded as an important epidemiological determinant for precipitating the disease (Radostits et al., 2007). Ganjam breeds of sheep and goats mostly managed by "Gola" community used to have regular movement from place to place in search of food during most parts of the year except rainy season thus easily coming into contact with infected animals during migration and contract the infection (Shuaib, 2011). Dusty and dry winds in cold chilled climatic conditions in winter months of December might favor the initiation of pneumonia by secondary saprophytic pathogens along with huddling of small ruminants in open grazing field favors the spread thus complicating the disease pathology (Saha et al., 2005).

\section{Clinical signs}

The flock showing 100\% morbidity with all the sheep and goats having increased vital parameters like temperature $\left(103.6 \pm 0.05^{\circ} \mathrm{F}\right)$, heart rate $(86 \pm 0.73 / \mathrm{min})$ and respiration rate $(38 \pm 0.54 / \mathrm{min})$ attributed to acute inflammatory response against invading pathogens (Islam et al., 2014). Prominent clinical abnormalities detected were refusal to feed, watery to white mucoid discharge from nose (Fig. 1) and eye, depression, salivation with necrotic ulcers or erosions throughout the oral cavity including tongue, gums, lips, cheek along with presence of a creamy color false diphtheritic membrane on dorsal surface of tongue (Fig. 2), suggestive for PPR (Chauhan et al., 2009). There was abortion in two does as per information from the herd owner. There was painful coughing, sneezing with production of wheezing sound or rales in most of the small ruminants. Soiling of hind quarter with soft and pasty blood stained faeces, evidence of respiratory difficulty mostly abdominal breathing in some kids characterized by extended head, abducted front legs, gasping with wide open mouth and extended tongue was observed. Denudation of hairs around the lips and muzzle with adhering dried discharge plugging the nose and gluing the eyelids were characteristic. Clinical findings as observed were in accordance with Islam et al., 2014. Stress associated with hot and humid climate interfere in the antioxidant system of animals causing free radical mediated cell injury through lipid peroxidation and thereby stimulate the adrenal medulla to produce increased concentration of epinephrine and nor-epinephrine producing adverse effect on hormonal system of the body, predisposing to infections in varying degree of clinical severity in animals (Cao et al., 2018).

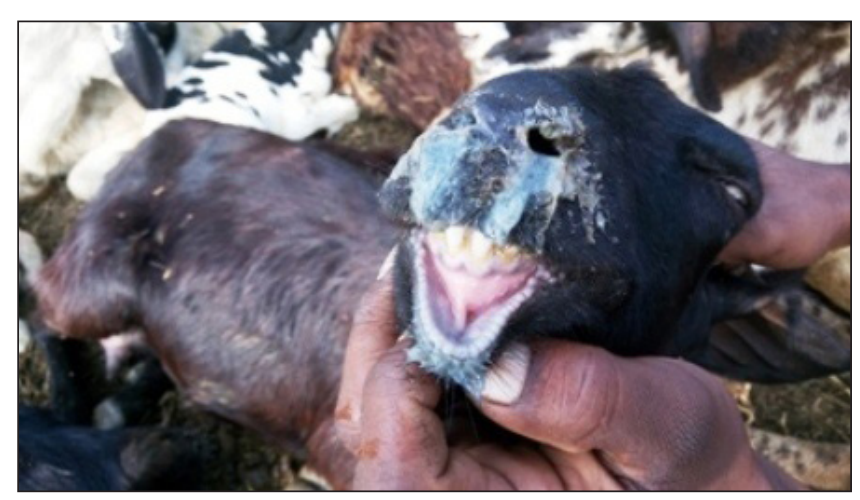

Fig. 1: Watery to white mucoid nasal discharges in PPR affected goat

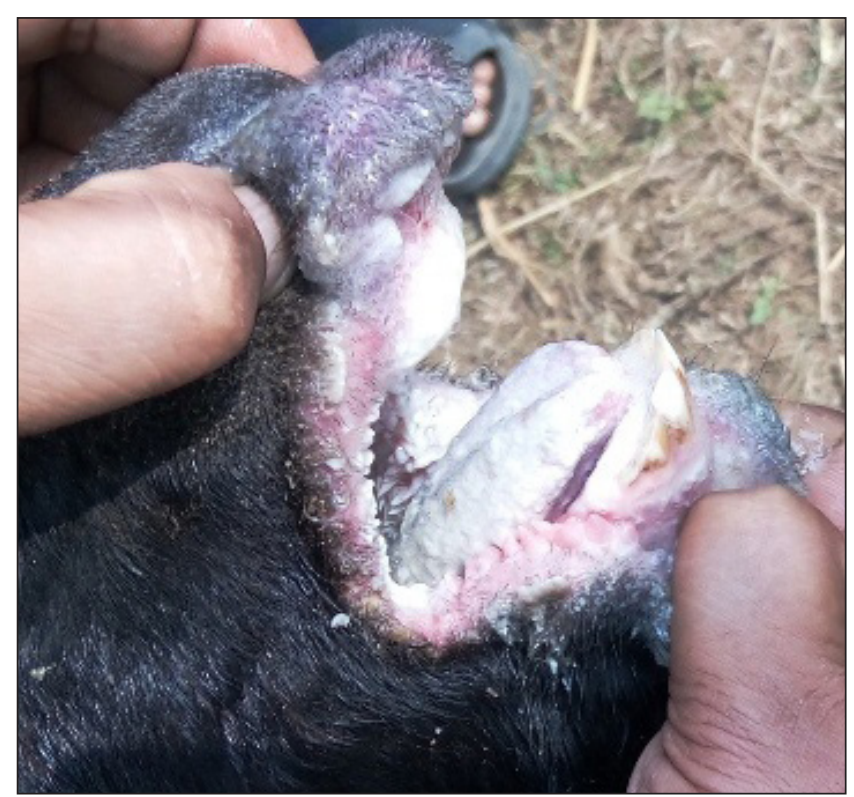

Fig. 2: Creamy color false diphtheritic membrane on dorsal surface of tongue in PPR

\section{Hematological examination}

The mean \pm SE values of all hematological parameters in both affected Ganjam goats and sheep as compared to the reference mean are presented in Table 1. Present 
investigation showed significant decrease ( $p \leq 0.05$ ) in $\mathrm{Hb}, \mathrm{TEC}$, and $\mathrm{PCV}$ in the affected small ruminants through one sample t-test. Decrease of various blood parameters was more pronounced in goats than sheep corroborating the clinical severity in goats (Birindwa et al., 2017) attributed to their genetic makeup, immune status and status of infection. Decrease in haematocrit values, erythrocyte counts were observed in the present investigation attributed to wide spread haemorrhages in various organs and bloody diarrhea (Sahinduran et al., 2012). Significant increase in total leucocyte count as well as Nutrophillia in affected sheep and goats associated with a positive immune response to the invading pathogen (Kataria and Kataria, 2004). Replication of PPR virus in lymphoid cells results lymphopaenia.

\section{Serum biochemical examination}

The Mean \pm SE values of different serum biochemical parameters are enlisted in Table 2. In this study, compared to reference values, significant decrease in glucose concentrations with a significant increase in kidney and liver profile parameters like creatinine, BUN, AST, ALT, in PPR affected sheep and goats observed through t-test which was in accordance with Sahinduran et al. (2012). Hypoglycaemia in morbid animals attributed to refusal to feed due to necrotic stomatitis. Altered serum biochemical concentrations might be due to replication of virus and damage to vital organs owing to inflammatory reactions in liver, kidney and lungs (Aziz et al., 2019).

\section{Gross lesions}

At necropsy, prominent morbid changes were carcasses with poor body condition, deep shrunken eyes signifying severe diarrhea with loss of body fat owing to emaciation, ulcers and erosions in dorsal aspect of tongue, gums, palate, pharynx, abomasums and esophagus besides emphysema and congestion observed in lungs. Bran like deposits in oral mucosa particularly tongue and hard palate, presence of exudates in trachea and bronchioles, firm and consolidated lungs (Fig. 3A) along with multiple petechial hemorrhages were characteristics in most of the carcasses. There was congested liver with multiple necrotic patches. Congestion of mesenteric mucosa along with enlarged hemorrhagic mesenteric lymphnode (Fig. 3B) throughout body was observed. Gross lesions observed in present study suggestive of PPR (Patel et al., 2017). Pale mucosa in some cases might be due to endoparasite infection. Except multiple linear hemorrhages and congested intestinal blood vessels and mesenteric lymphnode, typical zebra stripping in large intestine particularly near ileo-caecal valve was not consistent during necropsy signifying acute respiratory infection rather than intestinal involvement in this particular outbreak (Kihu et al., 2014).

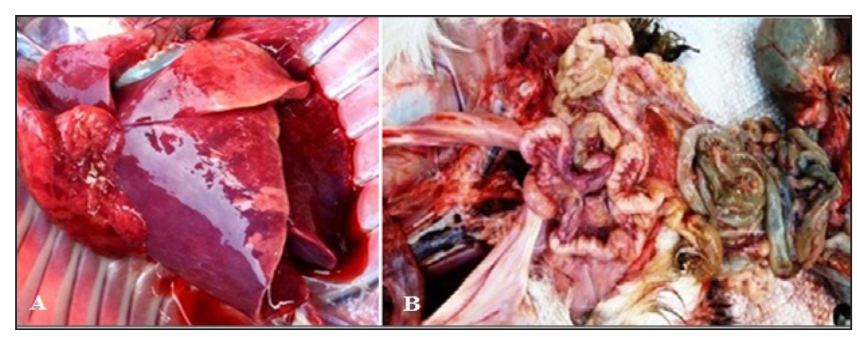

Fig. 3: Post mortem lesions of PPR affected sheep and goats showing (A) Firm consolidation of lungs, (B) congested mesenteric mucosa with hemorrhagic and enlarged mesenteric lymphnode

\section{Histopathological changes}

Significant histological lesions with certain degree of severity as observed mostly confined to respiratory and digestive organs as supported by earlier findings (Jaisree et al., 2017). Presence of intranuclear and/or intra cytoplasmic eosinophillic inclusion bodies along with multi-nucleated giant cells or syncytia were regarded as confirmatory or pathognomonic for PPR disease (Khan et al., 2018). Microscopic changes in tissues might be associated with inflammatory reaction combined with damaging effect of secondary bacterial, viral and parasites in co-association with PPRV (Zakian et al., 2016). Localization of PPR virus in the epithelial cells of gastrointestinal tract results in blunting and stunted intestinal villi with congestion and desquamation (Fig. $4 \mathrm{~A}$ ), goblet cell hyperplasia, infiltration of inflammatory mononuclear cells in lamina propria as well as sub mucosal edema were observed in intestine (Gitao et al., 2016). Necrosis of squamous epithelial cells, sloughing of tongue papillae with ulcerations and infiltrations of mononuclear cells and syncytia were common in tongue tissue through histopathology (Singh et al., 2018). Microscopic changes in lungs revealed infiltration of inflammatory cells, alveolar septal edema and thickening, 
alveolar dilatation, pinkish exudates in alveolar space, presence of intracytoplasmic eosinophillic inclusion body in alveolar epithelial cells (Fig. 4B) and bronchiolar lumen, desquamation of bronchiolar epithelium and/ or presence of intranuclear eosinophillic inclusion body and syncytia (Patel et al., 2017). Degeneration and necrotic changes in liver, mononuclear and nutrophillic infiltrations in hepatocytes with syncytia (Fig. 4C) and/or presence of inclusion bodies were observed in liver (Toplu et al., 2004). There was depletion of lymphoid cells as observed in mesenteric lymphnode and spleen attributing to lymphotropism of the PPR virus (Aktas et al., 2011). Glomerular atrophy, sloughing of renal tubular epithelial cells and increased bowman's space (Fig. 4D) were in agreement with Patel et al. (2015).

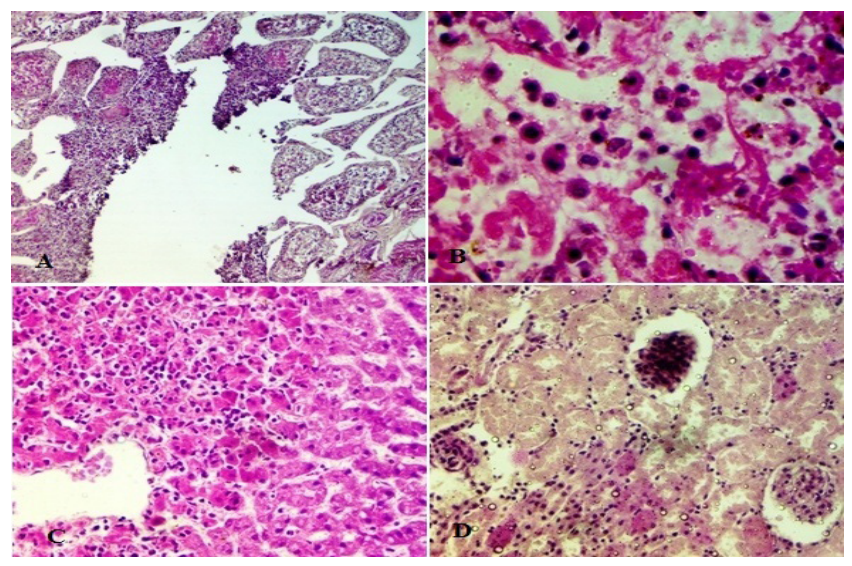

Fig. 4: Histopathological lesions showing (A) Blunting and stunting of intestinal villi, congestion and desquamation, (B) Intracytoplasmic eosinophillic inclusion body in alveolar epithelial cells, (C) Necrosis of hepatocytes and presence of inflammatory cells with syncytia, (D) Tubular degeneration, narrowing of tubular lumen and glomerular atrophy with increased Bowman's space

\section{CONCLUSION}

Present investigation was considered as first ever detailed description regarding the pathology of PPR in Ganjam sheep and goats in Odisha enlisting the typical clinical signs, altered haemato-biochemical parameters along with pathomorphological and microscopic changes of this emerging disease. Hot and humid climate, unchecked movement across open adjacent borders, nomadic pattern of rearing in open field predisposes the Ganjam goat and sheep most often for PPR influencing the livelihood of poor farmers. Awareness among the "Gola community" of Ganjam, Odisha along with intensification of mass vaccination is warranted to check the spread of disease.

\section{ACKNOWLEDGEMENTS}

Authors are thankful to Dean, College of Veterinary Science \& Animal Husbandry and to the field veterinarian and concerned animal owner for extending their cooperation and support during the study.

\section{REFERENCES}

Aktas, M.S., Ozkanlar, Y., Simsek, N., Temur, A. and Kalkan, Y. 2011. Peste des petits ruminants in suckling lambs case report. Isr. J. Vet. Med., 66(1): 39- 44.

Aziz, R.P., Sharma, S.K., Kuldeep, S.K., Yadav, H.S. and Kuntal, N. 2019. Hemato-biochemical and electrolyte alterations in a flock of goats affected with Peste des petits ruminants. J. Pharm. Innov., 8(4): 318-321.

Balamurugan, V., Saravanan, P., Sen, A., Rajak, K.K., Venkatesan, G., Krishnamoorthy P., Bhanuprakash, V. and Singh R.K. 2012. Prevalence of Peste des petits ruminants among sheep and goats in India. J. Vet. Sci., 13: 279.

Banyard, A.C., Parida, S., Batten, C., Oura, C., Kwiatek, O. and Libeau, G. 2010. Global distribution of peste des petits ruminants virus and prospects for improved diagnosis and control. J. Gen. Virol., 91: 2885-2897.

Benjamin, M.M. 2005. Outline of Veterinary clinical Pathology, $1^{\text {st }}$ Ed., Kalyani publisher, New Delhi, India.

Birindwa, B.A., George, G.C., Ntagereka, B.P., Christopher, O. and Lilly, B.C. 2017. Mixed infection of peste-des-petits ruminants and Capripox in goats in South Kivu, Democratic Republic of Congo. J. Adv. Vet. Anim. Res., 4(4): 348-355.

Cao, Z., Jin, Y., Shen, T. and Xu, F. 2018. Risk factors and distribution of peste des petits ruminants (PPR) in Mainland China. Small Rumin. Res., 162: 12-16.

Chauhan, H.C., Chandel, B.S., Kher, H.N., Dadawala, A.I. and Agrawal, S.M. 2009. Pesti des petits ruminants virus infection in animals. Vet. World., 2(4): 150-155.

Gibbs, E.P., Taylor, W.P., Lawman, M.J. and Bryant, J. 1979. Classification of peste des petits ruminants virus as the fourth member of the genus morbillivirus. Intervirology, 11: 268274.

Gitao, C., Kihu, S. and Maina, S. 2016. Review Of Peste des petits ruminants In Sheep. J. Vet. Med. Res., 3(5): 1060.

Gupta, S.D., Biswas, P.K., Habib, S. and Debnath, N.C. 2007. Prevalence of PPR in the greater Chittagong district of Bangladesh. Int. J. Anim. Fish. Sci., 3(2): 36-41. 
Hota, A., Biswal, S., Sahoo, N., Rout, M., Chaudhury, D., Pandey, A.B. and Muthuchelvan, D. 2018. seroprevalence of PPR among sheep and goats of different agroclimatic zones of Odisha. Int. J. Livest.Res., 8(4): 296-302.

Islam, M.S., Khan, M.S., Kader, H.A., Begum, M.R. and Asgar, M.A. 2012. Prevalence of PPR of goat and their response to antibiotic treatment at Mizaganj upazila of Patuakhali district. J. Environ. Sci. Nat. Resour., 5(2): 181-184.

Islam, K., Ahad, A., Mahmood, A., Rahman, M.M., Islam, Z.M., Kabir, H. Bin, Barua, M., Chowdhury, S., Nasir, M.K. and Biswas, P.K. 2014. Prevalence and clinico-pathological features of peste des petits ruminants. J. Inf. Mol. Biol., 2: 43-48.

Jaisree, S., Hemalatha, S., Muthuramalingam, T., Manimaran, K., Mahaprabhu, R., Gnanaraj, P.T., Kumann, K. and Roy, P. 2017. Investigation on outbreak of Peste des petits ruminants (PPR) in an organized farm among Tellicherry breed of goats. Int. J. Livest. Res., 7(1): 100-106.

Kataria, N. and Kataria, A.K. 2004. Use of blood analysis in assessment of stress due to drought in camel. J. Camel. Pract. Res., 11: 129-133.

Khan, A., Saleemi, M.K. and Ali, F. 2018. Pathophysiology of peste des petits ruminants in sheep (Dorpe \& Kajli) and goats (Boer \& Beetal). Microbiol. Pathol., 117: 139-147.

Kihu, S.M., Gitao, G.C., Bebora, L.C., Njenga, M.J., Wairire, G.G., Maingi, N., Wahome, R. G., Karanja, D.N., Oyugi, J.O. and Lutomia, E. 2014. Clinical, pathological and molecular investigations of Peste des petits ruminants virus infection in goats from Turkana county in Kenya. Br. J. Virol., 1(3): 98-102.

Kumar, P., Tripathi, B.N., Sharma, A.K., Kumar, R., Sreenivasa, B.P., Singh, R.P., Dhar, P., Bandyopadhyay, S.K. 2004. Pathological and immunohistochemical study of experimental peste des petits ruminants virus infection in goats. J. Vet. Med. B., 51: 153-159.

Obi, T.U. 1983. Studies on the epidemiology of PPR in Southern Nigeria, Trop. Vet., 1: 209-217.

Patel, J.M., Patel, D.R., Mavadiya, S.V., Solanki, J.B., Vihol, P.D., Sharma, K.K., Trangadia B.J. and Kalyani, I.H. 2015. Clinicopathological investigation of an outbreak of peste des petits ruminants in small ruminants in South Gujurat, India. Indian. J. vet. Pathol., 39(1): 20-23.
Patel, Y.R., Patel, J.M., Vihol, P.D., Kalyani, L.H., Solanki, J.B. and Panchal, P.P. 2017. Pathomorphological studies of Peste des petits ruminants (PPR) in goats of Navsari and Valsad districts, India. Int. J. Curr. Microbiol. Appl. Sci., 6(12): 238244.

Pope, R.A., Parida, S., Bailey, D., Brownlie, J., Barrett, T. and Banyard, A.C. 2013. Early events following experimental infection with Peste-Des-Petits ruminants virus suggest immune cell targeting. PLoS One, 8(2): e55830.

Radostits, O.M., Blood, D.C. and Gray, C.C. 2007. Veterinary Medicine: A text book of the disease of cattle, horse, sheep, pigs and goats, $10^{\text {th }}$ Edn. London, Elsevier.

Saha, A., Lodh, C. and Chakraborty, A. 2005. Prevalence of PPR in goats. Indian Vet. J., 82: 668-669.

Sahinduran, S., Albay, M.K., Sezer, K., Ozmen, O., Mamak, N., Haligur, M., Karakurum, C. and Yildiz, R. 2012. Coagulation profile, haematological and biochemical changes in kids naturally infected with peste des petits ruminants. Trop. Anim. Health. Prod., 44: 453-457.

Shuaib, Y.A. 2011. Peste des petits ruminants in sheep in Sudan: A study on sero-prevalence and risk factors, MSc thesis, Graduate School of Addis Ababa University, Department of Public Health, Faculty of Veterinary Medicine, Freie unversitat Berlin and Sudan University of Science and Technology, Sudan.

Singh, R., Singh, R., Singh, S., Kamdi, B., Kumari, S., Singh, R., Chauhan, P. and Husain A. 2018. Patho-morphological based diagnosis of Peste des petits ruminants (PPR) in goats. J. Anim. Res., 8(3): 545-548.

Toplu, N. 2004. Characteristic and non-characteristic pathological findings in peste des petits ruminants (PPR) of sheep in the Ege district of Turkey. J. Comp. Pathol., 31(23): 135-141.

Zakian, A., Nouri, M., Faramarzian, K., Tehrani-Sharif, M., Rezale, A. and Mokhber-Dezfouli, R. 2016. Comprehensive review on Peste des petitis ruminants (PPR) disease in ruminants and camels: with emphasis on clinical signs and histopathological finding. J. Vet. Sci. Med. Diagn., 5: 4. 
